\title{
Epigallocatechin-3-gallate inhibits cell growth, induces apoptosis and causes $S$ phase arrest in hepatocellular carcinoma by suppressing the AKT pathway
}

\author{
XIAOYUN SHEN，YONG ZHANG，YAN FENG，LITU ZHANG，JILIN LI，YU-AN XIE and XIAOLING LUO
}

Research Department, Affiliated Tumour Hospital of Guangxi Medical University, Nanning 530021, P.R. China

Received November 14, 2013; Accepted December 17, 2013

DOI: 10.3892/ijo.2014.2251

\begin{abstract}
Epigallocatechin-3-gallate (EGCG) has been shown to inhibit the growth and induce apoptosis of certain cancer cells. The aim of this study was to determine the role of EGCG in hepatocellular carcinoma (HCC) and the underlying mechanism(s) thereof. MTT assay was used to determine the cell growth inhibition by EGCG. Apoptosis induced by EGCG was investigated by both $\mathrm{AO} / \mathrm{EB}$ staining and flow cytometry. The cell cycle distribution was analyzed by flow cytometry. The mRNA levels of the AKT pathway were analyzed by quantitative PCR. The expression of AKT and its phosphorylation at Ser473 were detected by western blotting. The $\mathrm{IC}_{50}$ of EGCG at $48 \mathrm{~h}$ for HepG2, SMMC7721 and SK-hep1 cells were 74.7, 59.6 and $61.3 \mu \mathrm{g} / \mathrm{ml}$, respectively. Significantly higher proportion of SMMC7721 cells entered the S phase upon treatment with EGCG for $48 \mathrm{~h}$ compared with control cells. EGCG decreased the mRNA levels of PI3K, AKT and NF- $\kappa \mathrm{B}$. The protein levels of AKT decreased and its phosphorylation at Ser473 was downregulated with EGCG treatment. EGCG inhibited growth by affecting the cell cycle and induced apoptosis in different HCC cells by downregulating PI3K/ AKT activity. The results suggest the potential of EGCG as an anticancer agent in the prevention or treatment of HCC.
\end{abstract}

\section{Introduction}

Hepatocellular carcinoma (HCC) is one of the most prevalent cancers in the world, characterized by high mortality rate and poor prognosis (1). Lack of effective treatment options and late diagnosis are major reasons for the high mortality rate in HCC (2). A new therapeutic strategy to address these challenges cannot be overstated.

Green tea, compared with other teas, has a higher concentration of catechin. Epigallocatechin-3-gallate (EGCG) is a

Correspondence to: Dr Xiaoling Luo, Research Department, Affiliated Tumour Hospital of Guangxi Medical University, Nanning 530021, P.R. China

E-mail: samly0@163.com

Key words: Epigallocatechin-3-gallate, SMMC7721, cell cycle, apoptosis, pathway water-soluble catechin, which suppresses the multiplication of cancer cells and induces apoptosis (3-5). EGCG suppressed adhesion and invasion of hepatocarcinoma cells through antioxidant activity (6). EGCG inhibited the growth and metastasis of pancreatic cancer $(7,8)$ and colorectal cancer (9), reduced the incidence of esophageal cancer (10) and improved the prognosis of breast cancer (11). It also inhibited the growth of HepG2 cells (12).

The EGCG anticancer effect is mediated by the PI3K/ AKT signaling pathway. EGCG inhibited PI3K/AKT/mTOR signaling and promoted the apoptosis of B lymphocytes (5). It decreased the transcription of FoxO1 via the PI3K/AKT and MEK/ERK pathways in 3T3-L1 differentiation (13). EGCG inhibited PI3K/AKT activation, which enhanced apoptosis of T24 human bladder cancer cells (14).

The role of EGCG in proliferation or apoptosis via AKT pathway in HCC has yet to be reported. In this study, we reported on the ability of EGCG to inhibit cell growth in HepG2, SMMC7721 and SK-hep1 cell lines, in vitro. We also discovered that EGCG induced apoptosis and S phase arrest by affecting the PI3K/AKT pathway in SMMC7721 cells, in vitro.

\section{Materials and methods}

Cell lines and cell culture. All human hepatocellular carcinoma cell lines were obtained from Shanghai Institutes for Biological Sciences, Chinese Academy of Science, China. HepG2, SMMC7721 and SK-hep1 cells were cultured in Dulbecco's modified Eagle's medium (DMEM) supplemented with $10 \%$ fetal bovine serum, $100 \mathrm{U} / \mathrm{ml}$ penicillin and $100 \mu \mathrm{g} / \mathrm{ml}$ streptomycin (all from Hyclone, USA) at $37^{\circ} \mathrm{C}$ in a humidified incubator containing $5 \% \mathrm{CO}_{2}$. Cells were subcultured every two days when the density of cells reached $80 \%$.

MTT assay. The cell growth inhibition effect of EGCG (purity $\geq 95 \%$, Sigma-Aldrich, USA) was investigated using 3-(4, 5-dimethylthiazol-2-yl)-2, 5-diphenyl-2H-tetrazolium bromide (MTT) assay. In brief, HepG2, SMMC7721 and SK-hep1 cells were seeded in 96-well culture plates at a density of $4 \times 10^{3}$ cells per well overnight. After culture in serum-free DMEM for $2 \mathrm{~h}$, cells were treated with $0,40,80$ and $120 \mu \mathrm{g} / \mathrm{ml} \mathrm{EGCG}$ 
in DMEM with $10 \%$ FBS for 24,48 or $72 \mathrm{~h}$. To evaluate the cell viability, $20 \mu 1$ MTT $(5 \mu \mathrm{g} / \mathrm{ml}$ in culture medium, Sigma Chemical Co., USA) was added to each well and incubated at $37^{\circ} \mathrm{C}$ for $4 \mathrm{~h}$. After removing the supernatants, $150 \mu \mathrm{l}$ DMSO was added to each well. The optical density (OD) was measured at $492 \mathrm{~nm}$ using a microplate reader (Thermo Multiskan MK3, USA). The growth inhibition rate was calculated as follows: Growth inhibition rate $(\%)=[1-(\mathrm{OD}$ of treatment cells/OD of control cells)] x $100 \%$.

Apoptosis assay. HepG2, SMMC7721 and SK-hep1 cells were seeded in 6-well plates at a density of $2 \times 10^{4}$ cells per well overnight. HepG2, SMMC7721 and SK-hep1 were then treated with EGCG at concentration of 74.7, 59.6 and $61.3 \mu \mathrm{g} /$ $\mathrm{ml}$ respectively. Later, cells were stained with acridine orange (AO) and ethidium bromide (EB) using Normal/Apoptosis/ Necrosis identification kit (KeyGen, China), following the manufacturer's instructions. Apoptosis of HCC cells was observed under an IX51 inverted fluorescent microscope (Olympus, Japan).

Flow cytometry. SMMC7721 cells were treated with or without $59.6 \mu \mathrm{g} / \mathrm{ml} \mathrm{EGCG}$ in 6 -well culture plates for $48 \mathrm{~h}$. Approximately $1 \times 10^{6}$ cells were collected, washed with 1 X PBS and fixed with $70 \%$ ethanol at $-20^{\circ} \mathrm{C}$ overnight. Cells were then centrifuged and washed with PBS three times, re-suspended in $100 \mu \mathrm{l}$ RNase $\mathrm{A}$, incubated at $37^{\circ} \mathrm{C}$ for $30 \mathrm{~min}$, followed by staining with $400 \mu \mathrm{l}$ propidium iodide (PI) staining solution (BD Sciences, USA) and incubated at $4^{\circ} \mathrm{C}$ in the dark. Finally, DNA contents in stained nuclei were analyzed with a flow cytometer (Beckman coulter Epics XL, USA).

Annexin V-FITC analysis. SMMC7721 cells were treated with or without $59.6 \mu \mathrm{g} / \mathrm{ml}$ EGCG for $48 \mathrm{~h}$. Cells were then washed twice with PBS. Then they were stained with Annexin V and PI (BD Sciences) in binding buffer. Cells were then analyzed using flow cytometry (BD Caliber, USA).

RNA extraction and reverse transcriptase PCR. Total RNA was extracted from SMMC7721 cells treated with or without $59.6 \mu \mathrm{g} / \mathrm{ml}$ EGCG for $48 \mathrm{~h}$, using TRIzol reagent according to the manufacturer's instructions (Invitrogen, USA) and quantified by NanoDrop2000 (Thermo Scientific, USA). The cDNA was generated from $0.5 \mu \mathrm{g}$ total RNA using a ReverTra Ace ${ }^{\circledR}$ qPCR RT kit (Toyobo, Japan) following the manufacturer's protocol and stored at $-20^{\circ} \mathrm{C}$.

Quantitative PCR. The mRNA levels of PI3K, AKT and NF- $\kappa B$ were determined by qPCR using GoTaq ${ }^{\circledR} \mathrm{qPCR}$ Master Mix (Promega, USA) following the manufacturer's instructions. The GAPDH mRNA was used as an internal control to normalize the amount of the above mRNA in each sample. The primers designed were as follows: GAPDH forward, 5'-AAG GTG AAG GTC GGA GTC AAC-3', reverse: 5'-GGG GTC ATT GAT GGC AAC AAT A-3'; PI3K forward: 5'-TGG AAG CAG CAA CCG AAA C-3', reverse: 5'-CAT TGA GGG AGT CGT TGT-3'; AKT forward: 5'-GGC AAG GTG ATC CTG GTG AA-3', reverse: 5'-GGG ACA GGT GGA AGA ACA GC-3'; NF-кB forward: 5'-GTC ACT GCC CAG ACT TTA CT-3', reverse: 5'-GCT TCT CCA CTG AAA ATC CT-3'.
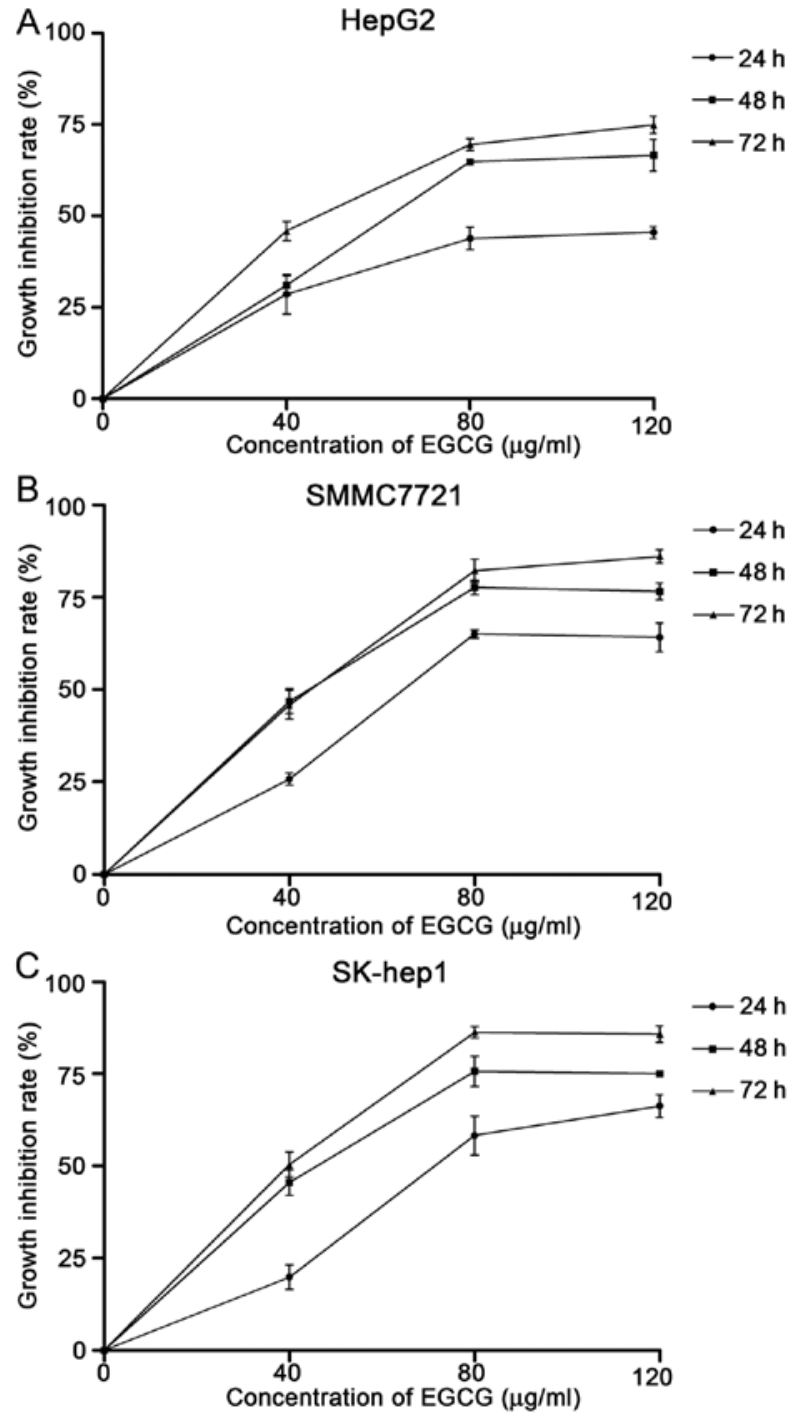

Figure 1. EGCG inhibits the growth of human hepatocellular carcinoma cells in vitro. HepG2 (A), SMMC7721 (B) and SK-hep1 (C) were treated with EGCG at concentrations of 0 (control), 40,80 or $120 \mu \mathrm{g} / \mathrm{ml}$ in DMEM with $10 \%$ FBS for 24 (circle), 48 (square) and $72 \mathrm{~h}$ (triangle). The growth inhibition rate for each cell line was analyzed by MTT assay and calculated. The data represent the mean \pm SD from three independent experiments.

All assays were performed in triplicate and calculated on the basis of $2^{-\Delta \Delta C t}$ method.

Western blot analysis. SMMC7721 cells were pretreated with EGCG, LY294002 (Cell Signaling Technology, USA), IGF-1 (R\&D Systems, USA) alone or with the combination of EGCG and LY294002 or IGF-1 for $48 \mathrm{~h}$. Protein extracts were prepared by RIPA lysis buffer [50 mM Tris ( $\mathrm{pH}$ 7.4), $150 \mathrm{mM}$ $\mathrm{NaCl}, 1 \%$ Triton $\mathrm{X}-100,1 \%$ sodium deoxycholate, $0.1 \%$ SDS, $2 \mathrm{mM}$ sodium pyrophosphate, $25 \mathrm{mM} \beta$-glycerophosphate, $1 \mathrm{mM}$ EDTA, $1 \mathrm{mM} \mathrm{Na} \mathrm{VO}_{4}$ ] adding $0.5 \mu \mathrm{g} / \mathrm{ml}$ leupeptin, $1 \mathrm{mM}$ PMSF and $10 \mathrm{mM} \mathrm{NaF}$. Protein concentration was quantified by BCA kit (Beyotime, China) according to the manufacturer's protocol. Proteins $(40 \mu \mathrm{g})$ were electrophoresed on $10 \%$ SDS-polyacrylamide gels and transferred to PVDF membranes. Membranes were probed with antibodies to AKT, p-AKT (Ser473) and $\beta$-actin. All antibodies were 


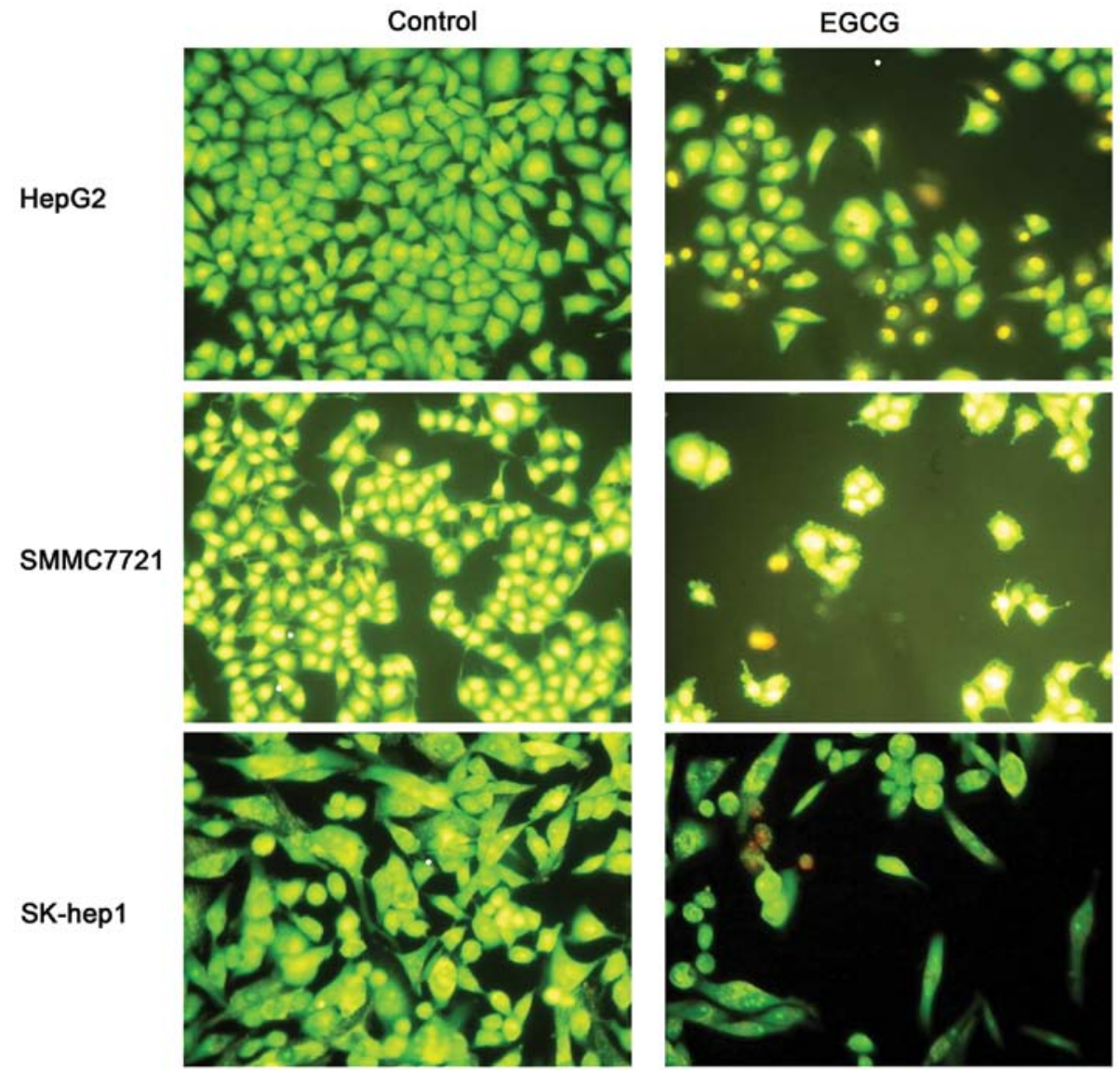

Figure 2. AO/EB staining shows EGCG induced apoptosis of human hepatocellular carcinoma cells. HepG2, SMMC7721 and SK-hep1 cells were treated with EGCG for $48 \mathrm{~h}$ at concentration of 74.71, 59.6 and $61.3 \mu \mathrm{g} / \mathrm{ml}$, respectively. Apoptotic cells were then detected with AO/EB double staining. Untreated cells (control) showed normal structure without prominent apoptosis and necrosis. Late apoptosis was seen in 48-h incubated cells (EGCG), represented by orange stain. Cells were visualized at x400 magnification. Representative results of three independent experiments are shown.

purchased from Cell Signaling Technology. Immunoreactive bands were visualized using the DyLight ${ }^{\circledR} 680$ Conjugateanti-rabbit IgG (Cell Signaling Technology). Bands were then scanned and analyzed by Odyssey two-color infrared imaging system (LI-COR, USA).

Statistical analysis. Differences between the two groups were analyzed with the Student's t-test unless indicated otherwise. Results were considered statistically significant at a $\mathrm{P}<0.05$.

\section{Results}

EGCG inhibits the growth of human hepatocellular carcinoma cells in vitro. To investigate the effect of EGCG on hepatocellular carcinoma cells, HepG2, SMMC7721 and SK-hep1 cells were treated with EGCG at different concentrations and time-points. The inhibition rate was calculated, based on the cell viability, determined by MTT assay. As shown in Fig. 1, the inhibition rate increased with the increase in concentration of EGCG across all three cell lines (Fig. 1). The cell growth inhibition rates at $48 \mathrm{~h}$ were significantly higher compared with rates at $24 \mathrm{~h}$, at each concentration in all cell lines. However, the difference between rates at 48 and $72 \mathrm{~h}$ following treatment was not significant. As a result, we chose 48 -h pretreatment in the following experiments. The half maximal (50\%) inhibitory concentrations $\left(\mathrm{IC}_{50}\right)$ of EGCG at $48 \mathrm{~h}$ for HepG2, SMMC7721 and SK-hep1 were 74.7, 59.6 and $61.3 \mu \mathrm{g} / \mathrm{ml}$, respectively (Fig. 1).

EGCG induces apoptosis. We next measured apoptosis in the presence of EGCG, as apoptosis was closely related to cell growth. Each cell line was treated with EGCG at $\mathrm{IC}_{50}$ concentration for $48 \mathrm{~h}$. The cell numbers of EGCG-treated group were significantly less than the control group (Fig. 2). Untreated cells (control) showed normal structure without prominent apoptosis and necrosis. The AO/EB staining indicated late apoptosis in 48-h incubated cells (Fig. 2), represented by orange staining. Flow cytometry also confirmed induction of apoptosis by EGCG in SMMC7721 cells. In EGCG-treated SMMC7721 cells, increased early and late apoptosis were observed (Fig. 3A). The total percentage of apoptosis (sum up of early stage and late stage) was $25.1 \pm 4.2 \%$ in EGCG-treated cells, compared with $9.0 \pm 2.7 \%$ in the non-treated control cells (Fig. 3B).

EGCG treatment arrests SMMC7721 cells at $S$ phase. To further investigate the underlying mechanism, we analyzed distribution of the cell cycle by flow cytometry (Fig. 4). After 48-h treatment, the percentage of EGCG-treated SMMC7721 cells in $\mathrm{S}$ phase was significantly higher compared with non-treated cells $(49.7 \pm 1.2$ vs. $22.1 \pm 1.5 \%$, Fig. 4). This result suggested that EGCG arrested SMMC7721 cells at S phase. 

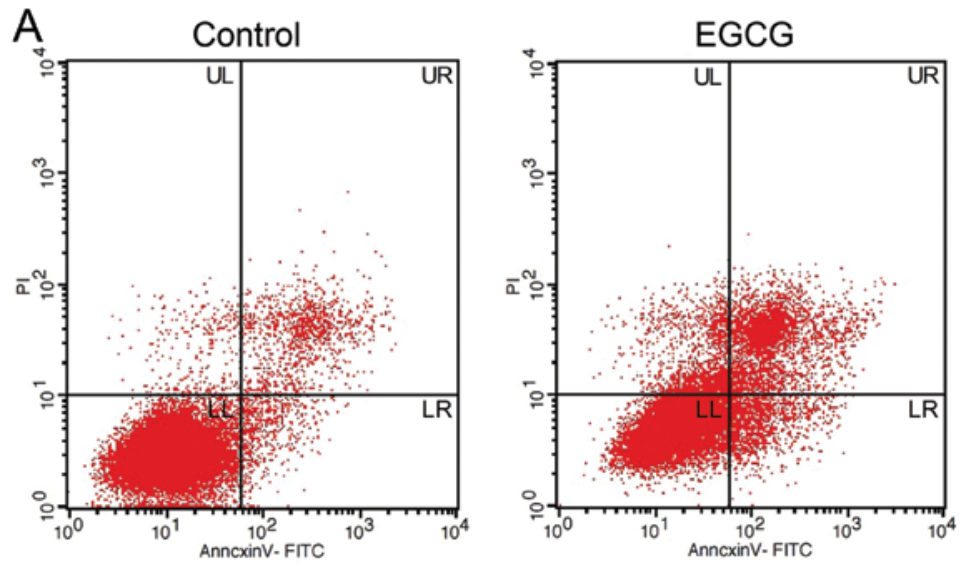

B

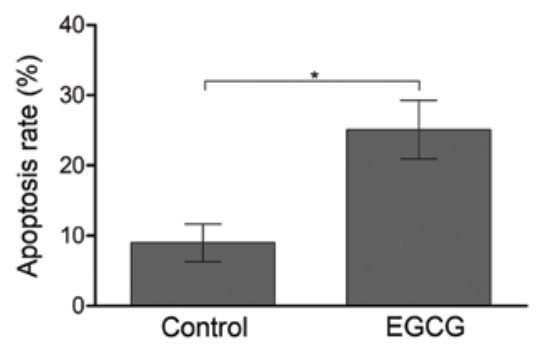

Figure 3. EGCG increased both early and late apoptosis of SMMC7721 cells. (A) Effect of EGCG treatment on apoptosis of SMMC7721 cells. Cells were incubated with $59.6 \mu \mathrm{g} / \mathrm{ml}$ EGCG (EGCG) or DMEM (control) for $48 \mathrm{~h}$. The cytograms were obtained by Annexin V and PI staining. Representative cytograms from three independent experiments are shown. (B) The histograms were obtained by Annexin V and PI staining. The results are presented as mean \pm SD of three independent experiments. ${ }^{*} \mathrm{P}<0.01$, compared to control.
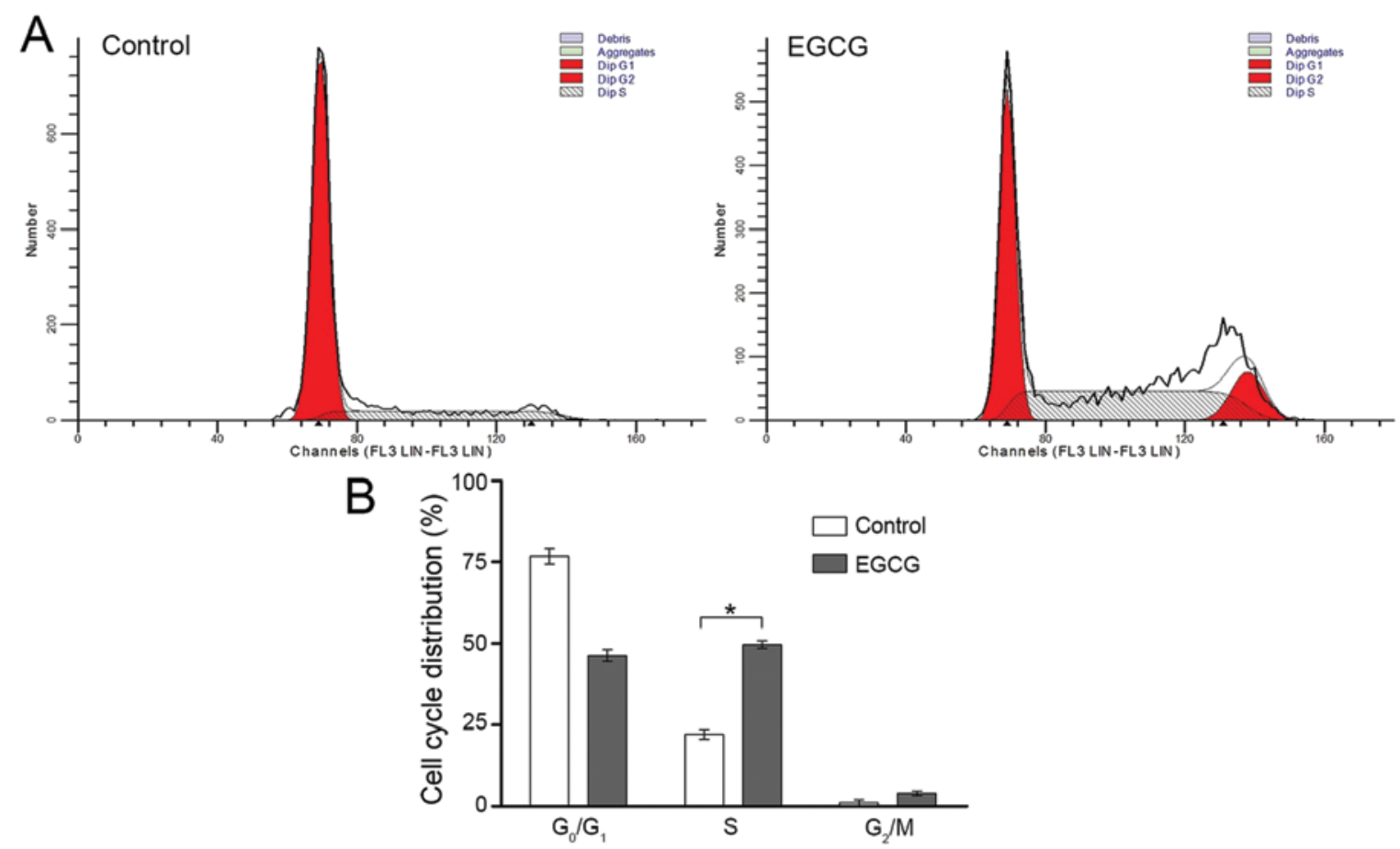

Figure 4. EGCG treatment arrests SMMC7721 cells at S phase. (A) SMMC7721 cells were treated with or without $59.6 \mu \mathrm{g} / \mathrm{ml} \mathrm{EGGC} \mathrm{for} 48 \mathrm{~h}$. The first peak represents cells in G1 phase, the second peak represents cells in G2/M phase and the area between the two peaks represents S phase. Representative results of three independent experiments are shown. (B) The histograms were obtained using PI staining followed by flow cytometry. The results are presented as mean \pm SD of three independent experiments. ${ }^{*} \mathrm{P}<0.01$, compared to control.

EGCG decreases the transcription of PI3K and AKT. We further investigated the role of AKT pathway mediating EGCG function in SMMC7721 cells. The mRNA level of
AKT was quantified by qPCR (Fig. 5). The results showed that relative mRNA levels of PI3K and AKT decreased $~ 31$ and $29 \%$ respectively, after treatment with EGCG compared with 

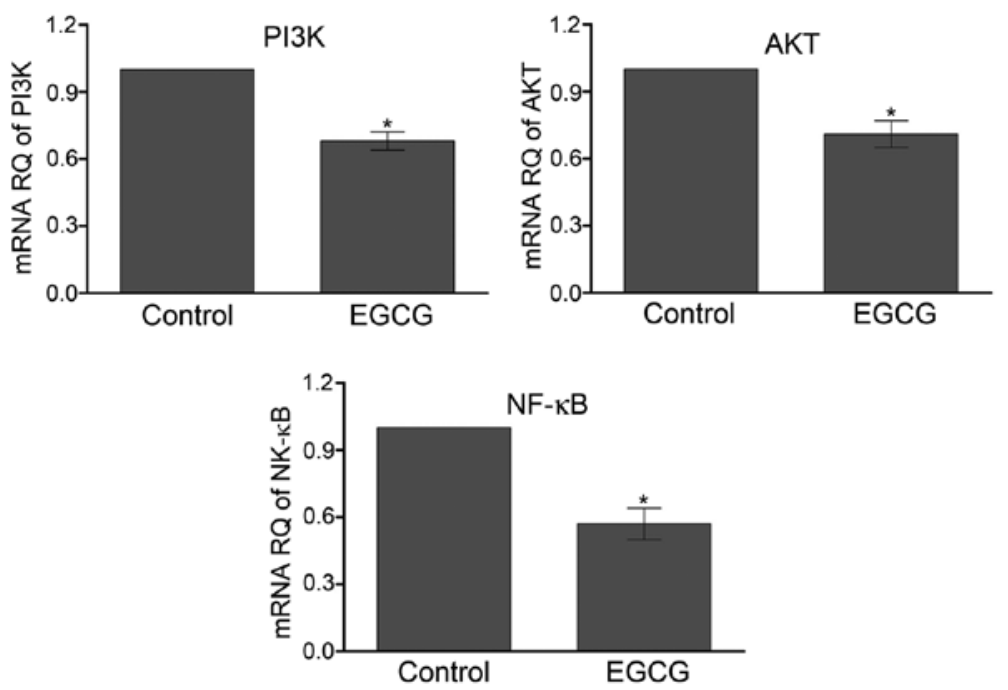

Figure 5. EGCG downregulates the transcription of AKT-pathway related genes. The mRNA levels were measured by qPCR and the relative quantification $(\mathrm{RQ})$ was normalized by $\beta$-actin. The data are expressed as mean $\pm \mathrm{SD}$ of three independent experiments. ${ }^{*} \mathrm{P}<0.05$.

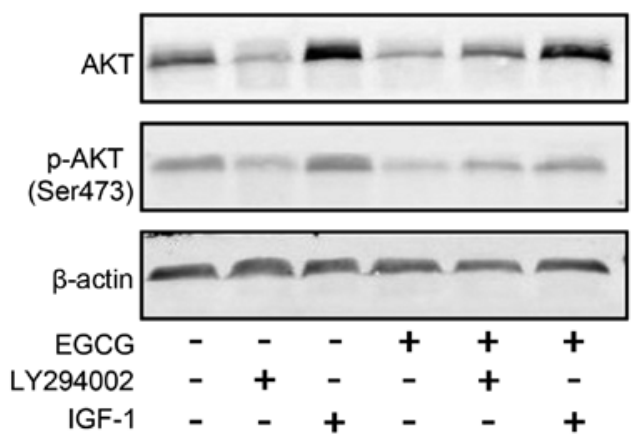

Figure 6. Effect of EGCG on AKT expression and its phosphorylation on SMMC7721. SMMC7721 cells were treated with EGCG $(59.6 \mu \mathrm{g} / \mathrm{ml})$, LY294002 $(2 \mu \mathrm{g} / \mathrm{ml})$, IGF-1 $(6 \mathrm{ng} / \mathrm{ml})$ alone or EGCG combined with LY294002 or IGF-1 for $48 \mathrm{~h}$. Western blotting was performed for AKT, p-AKT (Ser473) and $\beta$-actin. Representative results of at least three independent experiments are shown.

control. NF- $\kappa \mathrm{B}$ was the major downstream effector of AKT. The transcription of NF- $\kappa \mathrm{B}$ was $43 \%$ lower in the SMMC7721 cells treated with EGCG than control cells $(\mathrm{P}<0.05)$.

EGCG downregulates the expression of AKT and its phosphorylation. EGCG downregulated the activity of AKT. We also verified the phosphorylation of AKT at Ser473 in SMMC7721 cells treated with EGCG using western blotting. As expected, the expression and phosphorylation of AKT were both reduced following treatment (Fig. 6).

\section{Discussion}

HCC is characterized by high mortality rate and poor prognosis (1). HepG2, SMMC7721 and SK-hep1 are classic cell lines for studying HCC. Studies have shown that EGCG induced tumor apoptosis, and prevented tumor invasion and metastasis $(6,8,15-17)$. We therefore, used these cell lines to investigate the effect of EGCG on inhibition of cell growth and the underlying mechanism. We observed that EGCG halted cell growth and induced apoptosis of SMMC7721 cells, which was also confirmed in other HCC cell lines (Figs. 1-3). Further, we observed that the $\mathrm{IC}_{50}$ of these three $\mathrm{HCC}$ cell lines at $48 \mathrm{~h}$ ranged from 60 to $75 \mu \mathrm{g} / \mathrm{ml}$ (Fig. 1), which was in accordance with previous studies (17-19).

Progression through each phase of the cell cycle is regulated carefully to avoid proliferation under adverse conditions. Cells are arrested in G1, S and G2/M phases to prevent replication of damaged DNA or to prevent aberrant mitosis. Previous studies reported that EGCG blocked progression of the cell cycle at G1 phase in HCC lines (12), which is reportedly related to the activation of AMPK (12). However, we found that EGCG caused S phase but not G1 arrest in SMMC7721 cells (Fig. 4), which might be attributed to the unique features of HCC cell lines.

PI3K/AKT pathway was reported to play an important role in cancer proliferation and migration. Previous studies indicated the role of PI3K/AKT pathway in the development and progression of HCC cells, mainly reflected in the mechanism of liver cancer cell proliferation, differentiation and apoptosis (20-22). The effect of EGCG on PI3K/AKT pathway in carcinogenesis, progression and metastasis in various type of tumors, have been widely studied in breast cancer (23), pancreatic cancer (8), endometrial cancer (24) and thyroid carcinoma (25). Here, we first detected the mRNA level of major components of AKT pathway, and found that EGCG downregulated the PI3K, AKT and NF- $\mathrm{KB}$ (Fig. 4). Phosphorylation at Ser473 and Thr308, AKT activates the downstream signaling molecules including the NF- $\kappa \mathrm{B}$ and regulates cancer cell apoptosis (26-28). Phosphorylation of AKT at Ser473 in SMMC7721 cells was reduced by EGCG (Fig. 5), which was consistent with a previous study of HepG2 cells, reporting that EGCG induced apoptosis and caused a decrease in the $\mathrm{p}-\mathrm{IGF}-1 \mathrm{R}$ protein and its downstream signaling molecules including the p-ERK, p-Akt, p-Stat-3, and $\mathrm{p}-\mathrm{GSK}-3 \beta$ proteins (29).

EGCG affects both upstream and downstream targets of AKT. Previous reports showed that EGCG inhibited 
the thrombin-PAR1/PAR4-p42/p44 MAPKinase invasive signaling axis in hepatocellular carcinoma cells (30). HIF-1 $\alpha /$ VEGF function was also a therapeutic target for EGCG in cancer chemoprevention and anticancer therapy $(15,22)$. EGCG also delayed HCC cell growth through inhibition of Bcl-2 family $(16,19)$ or induced apoptosis in HCC cells via downregulation of COX-2 and Bcl-2, and consequently activated caspase- 9 and caspase-3 (31). The anti-metastatic effects of EGCG were associated with the inhibition of MMP-2 and MMP-9 activity $(32,33)$.

In conclusion, our study provides evidence that EGCG inhibited HCC cell growth by affecting cell cycle and inducing apoptosis via downregulation of PI3K/AKT activity. The results suggested that EGCG is a potential anticancer agent in HCC therapy.

\section{Acknowledgements}

This study was supported by grants from the Youth Science Foundation of Guangxi Medical University (no. 02602211011) and Guangxi Natural Science Foundation (no. 2013GXNSFBA0191865).

\section{References}

1. Jemal A, Bray F, Center MM, Ferlay J, Ward E and Forman D: Global cancer statistics. CA Cancer J Clin 61: 69-90, 2011.

2. Shek FH, Fatima S and Lee NP: Implications of the use of eukaryotic tanslation initiation factor 5A (eIF5A) for prognosis and treatment of hepatocellular carcinoma. Int J Hepatol 2012: 760928, 2012.

3. Hagen RM, Chedea VS, Mintoff CP, Bowler E, Morse HR and Ladomery MR: Epigallocatechin-3-gallate promotes apoptosis and expression of the caspase 9a splice variant in PC3 prostate cancer cells. Int J Oncol 43: 194-200, 2013.

4. Li JJ, Gu QH, Li M, Yang HP, Cao LM and Hu CP: Role of Ku70 and Bax in epigallocatechin-3-gallate-induced apoptosis of A549 cells in vivo. Oncol Lett 5: 101-106, 2013.

5. Liu D, Li P, Song S, et al: Pro-apoptotic effect of epigallo-catechin-3-gallate on B lymphocytes through regulating BAFF/PI3K/ $\mathrm{Akt} / \mathrm{mTOR}$ signaling in rats with collagen-induced arthritis. Eur J Pharmacol 690: 214-225, 2012

6. Zhang G, Miura Y and Yagasaki K: Suppression of adhesion and invasion of hepatoma cells in culture by tea compounds through antioxidative activity. Cancer Lett 159: 169-173, 2000.

7. Shankar S, Ganapathy S, Hingorani SR and Srivastava RK: EGCG inhibits growth, invasion, angiogenesis and metastasis of pancreatic cancer. Front Biosci 13: 440-452, 2008.

8. Shankar S, Marsh L and Srivastava RK: EGCG inhibits growth of human pancreatic tumors orthotopically implanted in Balb C nude mice through modulation of FKHRL1/FOXO3a and neuropilin. Mol Cell Biochem 372: 83-94, 2013.

9. Inaba $H$, Nagaoka $Y$, Kushima $Y$, et al: Comparative examination of anti-proliferative activities of (-)-epigallocatechin gallate and (--)-epigallocatechin against HCT116 colorectal carcinoma cells. Biol Pharm Bull 31: 79-84, 2008.

10. Li ZG, Shimada Y, Sato F, et al: Promotion effects of hot water on N-nitrosomethylbenzylamine-induced esophageal tumorigenesis in F344 rats. Oncol Rep 10: 421-426, 2003.

11. Kushima Y, Iida K, Nagaoka Y, et al: Inhibitory effect of (-)-epigallocatechin and (-)-epigallocatechin gallate against heregulin betal-induced migration/invasion of the MCF-7 breast carcinoma cell line. Biol Pharm Bull 32: 899-904, 2009.

12. Huang CH, Tsai SJ, Wang YJ, Pan MH, Kao JY and Way TD: EGCG inhibits protein synthesis, lipogenesis, and cell cycle progression through activation of AMPK in p53 positive and negative human hepatoma cells. Mol Nutr Food Res 53: $1156-1165,2009$

13. Kim H and Sakamoto K: (-)-Epigallocatechin gallate suppresses adipocyte differentiation through the MEK/ERK and PI3K/Akt pathways. Cell Biol Int 36: 147-153, 2012.
14. Qin J, Xie LP, Zheng XY, et al: A component of green tea, (-)-epigallocatechin-3-gallate, promotes apoptosis in T24 human bladder cancer cells via modulation of the PI3K/Akt pathway and Bcl-2 family proteins. Biochem Biophys Res Commun 354: 852-857, 2007.

15. Shirakami Y, Shimizu M, Adachi S, et al: (-)-Epigallocatechin gallate suppresses the growth of human hepatocellular carcinoma cells by inhibiting activation of the vascular endothelial growth factor-vascular endothelial growth factor receptor axis. Cancer Sci 100: 1957-1962, 2009.

16. Tsang WP and Kwok TT: Epigallocatechin gallate up-regulation of miR-16 and induction of apoptosis in human cancer cells. J Nutr Biochem 21: 140-146, 2010.

17. Uesato S, Kitagawa Y, Kamishimoto M, Kumagai A, Hori H and Nagasawa $\mathrm{H}$ : Inhibition of green tea catechins against the growth of cancerous human colon and hepatic epithelial cells. Cancer Lett 170: 41-44, 2001.

18. Abou El Naga RN, Azab SS, El-Demerdash E, Shaarawy S, El-Merzabani M and Ammar el SM: Sensitization of TRAILinduced apoptosis in human hepatocellular carcinoma HepG2 cells by phytochemicals. Life Sci 92: 555-561, 2013.

19. Nishikawa T, Nakajima T, Moriguchi M, et al: A green tea polyphenol, epigalocatechin-3-gallate, induces apoptosis of human hepatocellular carcinoma, possibly through inhibition of Bcl-2 family proteins. J Hepatol 44: 1074-1082, 2006.

20. Bu X, Jia F, Wang W, Guo X, Wu M and Wei L: Coupled down-regulation of mTOR and telomerase activity during fluorouracil-induced apoptosis of hepatocarcinoma cells. BMC Cancer 7: 208, 2007.

21. Tang C, Lu YH, Xie JH, et al: Downregulation of survivin and activation of caspase-3 through the PI3K/Akt pathway in ursolic acid-induced HepG2 cell apoptosis. Anticancer Drugs 20: 249-258, 2009.

22. Zhang Q, Tang X, Lu Q, Zhang Z, Rao J and Le AD: Green tea extract and (-)-epigallocatechin-3-gallate inhibit hypoxia- and serum-induced HIF-1alpha protein accumulation and VEGF expression in human cervical carcinoma and hepatoma cells. Mol Cancer Ther 5: 1227-1238, 2006

23. Zhang G, Wang Y, Zhang Y, et al: Anti-cancer activities of tea epigallocatechin-3-gallate in breast cancer patients under radiotherapy. Curr Mol Med 12: 163-176, 2012.

24. Park SB, Bae JW, Kim JM, Lee SG and Han M: Antiproliferative and apoptotic effect of epigallocatechin-3-gallate on Ishikawa cells is accompanied by sex steroid receptor downregulation. Int J Mol Med 30: 1211-1218, 2012.

25. De Amicis F, Perri A, Vizza D, et al: Epigallocatechin gallate inhibits growth and epithelial-to-mesenchymal transition in human thyroid carcinoma cell lines. J Cell Physiol 228: 2054-2062, 2013.

26. Dang TP: Notch, apoptosis and cancer. Adv Exp Med Biol 727: 199-209, 2012.

27. Datta SR, Brunet A and Greenberg ME: Cellular survival: a play in three Akts. Genes Dev 13: 2905-2927, 1999.

28. Roos WP and Kaina B: DNA damage-induced cell death: from specific DNA lesions to the DNA damage response and apoptosis. Cancer Lett 332: 237-248, 2013.

29. Shimizu M, Shirakami Y, Sakai H, et al: EGCG inhibits activation of the insulin-like growth factor (IGF)/IGF-1 receptor axis in human hepatocellular carcinoma cells. Cancer Lett 262: 10-18, 2008.

30. Kaufmann R, Henklein P, Henklein P and Settmacher U: Green tea polyphenol epigallocatechin-3-gallate inhibits thrombininduced hepatocellular carcinoma cell invasion and $\mathrm{p} 42 /$ p44-MAPKinase activation. Oncol Rep 21: 1261-1267, 2009.

31. Chen XL, Wang Q, Cao LQ, et al: Epigallocatechin-3-gallate induces apoptosis in human hepatocellular carcinoma cells. Zhonghua Yi Xue Za Zhi 88: 2524-2528, 2008 (In Chinese).

32. Roomi MW, Monterrey JC, Kalinovsky T, Rath M and Niedzwiecki A: Comparative effects of EGCG, green tea and a nutrient mixture on the patterns of MMP-2 and MMP-9 expression in cancer cell lines. Oncol Rep 24: 747-757, 2010.

33. Zhang Y, Owusu L, Duan W, et al: Anti-metastatic and differential effects on protein expression of epigallocatechin-3-gallate in HCCLM6 hepatocellular carcinoma cells. Int J Mol Med 32: 959-964, 2013. 